\title{
Propostas pedagógicas ou curriculares: Subsídios para uma leitura crítica
}

\begin{abstract}
RESUMO: Este trabalho, de natureza teóricoprática, visa apresentar uma alternativa de análise e construção de currículo. Foi produzido a partir de atividades de assessoria, acompanhamento e avaliação de políticas públicas de educação de diferentes órgãos públicos, especialmente municipais, e está baseado em pesquisas na área, tendo o objetivo de subsidiar a análise crítica de propostas pedagógicas ou curriculares. O texto é orientado pela teoria crítica da cultura e a autora parte do pressuposto de que toda proposta pedagógica é expressão de um projeto político e cultural. Destina-se em particular a profissionais que atuam nas redes de ensino regular. A análise aqui desenvolvida tenta sistematizar as principais questões que precisam ser respondidas na elaboração de projetos curriculares.
\end{abstract}

Sonia Kramer*

Palavras-chave: Mudança, proposta pedagógica, currículo, formação em serviço, política pública de educação

Introdução

Nos últimos 15 anos, inúmeras questões relativas a currículo elaboração, implementação, legislação - têm suscitado, nos mais diversos fóruns, seja de natureza acadêmica, política ou sindical, interessantes embates e discussões. Na verdade, desde o momento em que reconquistamos o direito de eleger, pelo voto, os projetos (e não só os governantes) de gestões, em primeiro lugar estaduais (1982), em segui-

* Professora do Departamento de Educação da PUC-Rio. 
da municipais (1985) e, mais recentemente, para o governo federal (1990), tem-se mostrado concreta a possibilidade de desenvolver diferentes alternativas práticas de ação no campo educacional. Menos visível nos municípios de grande porte, e mais efetiva em redes menores e em conjunturas políticas mais maduras, o ponto central é o de que, felizmente, temos hoje uma pluralidade de caminhos bem mais interessantes, e, a meu ver, efetivos, do que nos anos dos acordos MEC-Usaid, que vinham junto com atos institucionais e práticas educacionais de triste lembrança para nossa geração.

Por outro lado, nos últimos dois anos, esse debate tornou-se mais caloroso diante das discussões em torno da nova LDB, que deveria definir bases e diretrizes para a educação brasileira, e da polêmica em torno dos chamados Parâmetros Curriculares. Nesse contexto, questões de caráter político, como não poderia deixar de ser dada a natureza política do campo educacional, estão subjacentes tanto à proposta do governo quanto às críticas a ela direcionadas. De minha parte, considerei grave em todo este processo a metodologia adotada para a elaboração dos parâmetros curriculares nacionais. Por quê? Por ter previsto um caminho pouco claro para sua elaboração, o que, pareceu-me, iria comprometer sua implementação. Buscando pareceres de especialistas isolados, sem fomentar a discussão ampla e organizada de setores e categorias profissionais de diferentes níveis (professores, pesquisadores, cientistas) e de todos os interessados nessa questão, sem provocar a participação da população que, na história deste país, tem sido alijada deste processo, sem ter uma dimensão formadora, produtora de inquietações, de levantamento de perguntas e de busca de respostas, pareceu-me, desde o início, que estávamos retomando rotas já percorridas. Sobretudo, incomodavame o fato de que já sabíamos que a prática pedagógica não é transformada a partir de propostas bem escritas; necessariamente, a transformação exige condições concretas de trabalho e salário e modos objetivos que operacionalizem a ampla participação na produção da proposta, de compreensão e de estudo, muitas vezes necessário, de confronto de idéias e de tempo para a tomada de decisões organizadas. Isso tudo configuraria uma situação de legitimidade imprescindível para que a educação fosse colocada em questão e que novos parâmetros fossem definidos; que se pudesse discutir, propor formas positivas de concretizá-la com qualidade e repensar as experiências existentes; e isso feito com emancipação cultural, aprendizado e com exercício de cidadania. 
Mas não foi assim que os governantes de hoje e suas equipes entenderam que deveria ser feito e não vou entrar aqui no mérito de tentar compreender se isso se deve à pressão de órgãos internacionais, à influência de instituições nacionais privadas ou à falta de visão políticoadministrativa capaz de gerar o entendimento de que não é por decreto, de "afogadilho", que se fazem as mudanças em educação. De meu ponto de vista, perdemos mais uma rica e interessante oportunidade de provocar situações, por meio das quais, de forma coletiva e organizada, os profissionais, as crianças, os jovens e os adultos que freqüentam as escolas e a população em geral pudessem pensar a educação que temos hoje, discutir a que queremos, e compreender o que precisamos fazer, questionar e mudar para conquistá-la.

Aproveito para esclarecer que, há um ano, não aceitei o convite que me foi feito para elaborar um parecer técnico sobre o texto dos parâmetros porque considerei o caminho inócuo; não levantei nenhuma bandeira pela não-elaboração do parecer, da mesma forma que não condenei aqueles que o fizeram. Apenas questionei as estratégias adotadas (contratação de peritos para apreciação individualizada; tempo reduzido destinado à tarefa; não-previsão de instâncias progressivas e organizadas para a análise crítica; não-explicitação dos critérios que seriam utilizados na compatibilização dos pareceres, especialmente os de caráter divergente etc.), além de têlas considerado eficazes, pelo menos com base na minha experiência em pesquisa lidando com teorias da linguagem, cultura e circulação do conhecimento, e com base na prática em intervenção educacional, mudança curricular e formação de professores.

Agora, minha intenção não é a de polemizar sobre estas questões, mas a de apresentar uma contrapalavra, no sentido que utiliza Mikhail Bakhtin (1992), ou seja, trazer uma réplica, uma alternativa ou proposição crítica, tomando a questão curricular e desenvolvendo-a pelo avesso ou, como diz Walter Benjamin (1987a), escovando-a a contrapelo, quer dizer, na direção contrária à habitual. Interessam-me aqui, como interlocutores, aqueles que estão efetivamente envolvidos na tarefa de pesquisar ou de colocar em prática o trabalho educativo, revendo propostas curriculares, delineando projetos voltados à sua reestruturação, atuando na formação permanente dos profissionais, passo essencial para que as mudanças sejam postas em ação, e para que a melhoria da qualidade seja conquistada.

Acredito que este artigo possa trazer algumas contribuições tanto para a análise e elaboração de propostas curriculares, quanto para a in- 
vestigação relativa ao delineamento de desenhos curriculares, tema que passa a receber, como vimos, tanta atenção da e na área educacional. E enfatizo que, mais do que trazer resposta, minha intenção é a de levantar as perguntas que, a meu ver, podem movimentar processos de elaboração destas propostas.

Este trabalho tem, portanto, uma natureza teórico-prática e foi produzido com o objetivo de subsidiar a análise crítica de propostas pedagógicas para a educação. Ele é, pois, um instrumento de trabalho, que vem sendo elaborado com base em diversos tipos de solicitações que tenho recebido (de secretarias municipais e estaduais de educação, de desenvolvimento e promoção social e do próprio Ministério de Educação) e de diferentes modos de inserção em projetos de Órgãos Não-Governamentais, de instituições privadas etc. Baseia-se em pesquisas na área e na atividade de assessoria e acompanhamento a políticas públicas de educação, em especial de crianças e jovens. ${ }^{1}$

No processo de elaboração deste texto, optei por uma abordagem crítica da cultura, partindo do pressuposto de que toda proposta pedagógica é expressão de um projeto político e cultural. Nesse sentido, a análise aqui sugerida ultrapassa o enfoque escolar ou administrativo que, freqüentemente, tem marcado as propostas educacionais, embora também considere os esforços que, em nome desta visão, têm sido feitos tanto para a compreensão quanto para a implementação de propostas pedagógicas.

Procuro, em primeiro lugar, discutir o que entendo por proposta pedagógica e apontar alguns aspectos controversos subjacentes a este tema na sociedade contemporânea, alertando para certos princípios que, a meu ver, precisam ser levados em conta tanto do ponto de vista de seu delineamento, quanto de sua concretização. Em segundo lugar apresento, com base na discussão desenvolvida, sugestões de critérios orientadores da análise crítica de propostas pedagógicas. Aqui, meu fundamento teórico é o de que analisar ou avaliar significa necessariamente fazer leitura de textos (falados ou escritos) e este é o aspecto a que dou prioridade, encaminhando critérios orientadores e organizadores desta leitura de propostas no que se refere ao(s) autor(es) da proposta e seu processo de produção, ao texto produzido e aos interlocutores (ouvintes, leitores) a que se dirige a proposta. No terceiro momento, sugiro procedimentos e critérios para a análise e a avaliação de modos de implementação de propostas em diferentes níveis. Vale assinalar que diversas das idéias apre- 
sentadas neste trabalho encontram-se mais desenvolvidas em outros textos que estão relacionados nas notas e na bibliografia, ao final.

Devo esclarecer, ainda, que não estabeleço diferença conceitual entre proposta pedagógica e currículo. Compreendo, assim, currículo ou alternativa curricular de forma ampla, dinâmica e flexível, que é freqüentemente a maneira com que se tem concebido uma proposta pedagógica. Identifico ambos os termos, portanto, relacionando-os à vida na escola, na creche, na pré-escola. Um currículo ou uma proposta pedagógica, assim definidos, reúnem tanto bases teóricas quanto diretrizes práticas neles fundamentadas, bem como aspectos de natureza técnica que viabilizam sua concretização.

\section{0 que é proposta pedagógica ou curricular?}

Uma proposta pedagógica é um caminho, não é um lugar. Uma proposta pedagógica é construída no caminho, no caminhar. Toda proposta pedagógica tem uma história que precisa ser contada. Toda proposta contém uma aposta. Nasce de uma realidade que pergunta e é também busca de uma resposta. Toda proposta é situada, traz consigo o lugar de onde fala e a gama de valores que a constitui; traz também as dificuldades que enfrenta, os problemas que precisam ser superados e a direção que a orienta. E essa sua fala é a fala de um desejo, de uma vontade eminentemente política no caso de um proposta educativa, e sempre humana, vontade que, por ser social e humana, nunca é uma fala acabada, não aponta "o" lugar, "a" resposta, pois se traz "a" resposta já não é mais uma pergunta. Aponta, isto sim, um caminho também a construir.

Para apresentar de forma mais viva essa maneira de conceber uma proposta pedagógica, vale lembrar da história que Benjamin (1987b, pp. 219-220) conta, falando de um rei que, apesar de muito poderoso, não se sentia feliz e se tornava cada vez mais melancólico. Mandou um dia chamar seu cozinheiro particular, pedindo-lhe que fizesse uma omelete de amoras tal qual havia saboreado há 50 anos, na sua infância. Nessa época, seu pai guerreava e, tendo perdido a guerra, tivera de fugir. Depois de muito vagar pela floresta, famintos e fatigados, o menino-rei e o pai encontraram uma choupana onde uma velha os fez descansar e lhes preparou uma torta de amoras. O cozinheiro - que recebera do rei, como promessa, a mão da filha e o reino, caso soubesse fazer aquela omelete, ou a morte, em caso negativo - escolhera de antemão morrer, já que, embora possuise os ingredientes e a receita da torta, jamais conseguiria temperá-la com 
o gosto do perigo da batalha, da vigilância do perseguido, do calor do fogo e da doçura do descanso, do presente exótico e do futuro obscuro.

Por que contar isso num texto de subsídios para análise de propostas? Porque toda vez que uma nova proposta educativa está sendo elaborada e que estão sendo planejadas as formas de colocá-la em prática, parece que ela se configura como uma promessa e como a ilusão de trazer uma alternativa mágica, supostamente sempre melhor que a anterior, com um modo de fazer mais eficiente, melhores resultados, soluções etc. E também porque, freqüentemente, os programas de intervenção educacional e as políticas de formação de profissionais da educação são carregados de expectativas, principalmente por parte daqueles que, seja de uma secretaria de educação, seja da universidade, concebem a nova proposta. É bem certo que este culto do sempre melhor, do mais novo, do mais moderno, traz os ecos deste nosso tempo - a modernidade - no qual o futuro tornou-se o equivalente de superação. É contraditória também a modernidade, principalmente se se levar em conta o avanço tecnológico e a realidade concreta de milhões de crianças e adultos em situação de miséria, desemprego, abandono. Como falar em futuro e superação, sem pontuar que a modernização historicamente não se fez acompanhar pela melhora das condições de vida da maior parte da população?

$\mathrm{Na}$ modernidade, o conceito de melhor é análogo ao de novo. Em educação, costumamos chamar de tradicional tudo o que nos desagrada. Corre-se atrás do melhor como se corre atrás do novo: o novo assunto, o novo método, a nova proposta, o novo currículo. Mas de que é feito esse novo que tanto seduz? Da negação do já existente que se passa a chamar de velho. Esta também tem sido a lógica que vem orientando as propostas pedagógicas: lógica de atualização, que nega a experiência acumulada em troca daquilo que se chama de moderno. Como ironizava Brecht (apud Kramer 1993b, pp. 167-168), apagam-se os rastros e abdica-se da capacidade de deixar traços ou marcas, ao aceitar que alguém traga esse novo pronto. Abdica-se da história, portanto. Ocorre que mesmo esse novo, que parece tão seguro, trai a expectativa que carrega, por ser esvaziado do conteúdo que dele se esperava. Já na década de 1930, filósofos como Benjamin (1987a), que pensavam criticamente a cultura e a modernidade, já indagavam: Por que o moderno envelhece tão rápido? Por que as propostas pedagógicas envelhecem tão rápido, pode-se aqui indagar. Talvez por não terem sido geradas por perguntas vivas de uma comunidade atuante e reconhecida como tal, por reificarem respostas de um lugar que não é o seu. 
Uma política pública deve propor, mas freqüentemente chama-se de proposta o que é modelo, método ou grade curricular. É preciso propor caminhos, levantando perguntas e gerando perguntas, experimentando caminhos, ao invés de pretender trazer saídas prontas e adoradas como bezerros de ouro. ${ }^{2}$ E se é função de uma política pública indicar diretrizes, ela precisa garantir as condições de implementá-la, assumindo que não há uma única saída, pretensamente melhor, mas múltiplas alternativas possíveis; e, além disso, contestar a busca desmedida e ilusória do futuro como superação, posto que seu preço tem sido o esquecimento da história, o congelamento do presente e a anulação das experiências vividas, desmobilizando as possibilidades de efetiva mudança, de transformação radical das condições que engendrariam, a partir do velho, o novo. E, assim sendo, o que se pode propor?

Uma nova proposta para a educação; um novo currículo é um convite, um desafio, uma aposta. Uma aposta porque, sendo parte de uma dada política pública, contém um projeto político de sociedade e um conceito de cidadania, de educação e de cultura. Portanto, não pode trazer respostas prontas apenas para serem implementadas, se tem em mira contribuir para a construção de uma sociedade democrática, onde a justiça social seja de fato um bem distribuído igualitariamente a toda coletividade. Uma proposta pedagógica expressa sempre os valores que a constituem, e precisa estar intimamente ligada à realidade a que se dirige, explicitando seus objetivos de pensar criticamente esta realidade, enfrentando seus mais agudos problemas. Uma proposta pedagógica precisa ser construída com a participação efetiva de todos os sujeitos - crianças e adultos, alunos, professores e profissionais não-docentes, famílias e população em geral -, levando em conta suas necessidades, especificidades, realidade. Isto aponta, ainda, para a impossibilidade de uma proposta única, posto que a realidade é múltipla, contraditória.

Buscando compreender a história com base em uma concepção crítica, Walter Benjamin (1984) chama a atenção para o hábito generalizador que faz olhar a realidade como se fosse única e também única a forma de olhar para ela. Sua preocupação é a de fazer justiça ao particular, de deixar que também ele fale, evitando que se dissolva na generalização, mas evitando também que o real se fragmente, não abdicando, pois, de uma dimensão de totalidade. Pensar uma proposta pedagógica única pressupõe pensar um conceito uniformizador de criança, de jovem, de adulto; de professor, de educação e de sociedade, um conceito 
que, por generalizar, desrespeita as diferenças - seja de etnia, sexo, classe social ou cultura. Ao contrário, uma proposta pedagógica ou curricular para a educação de crianças, de jovens ou de adultos precisa trabalhar com as contradições e especificidades da realidade brasileira, de cada região, estado ou município, zona urbana ou rural. Por isso, não se pode falar de uma proposta, mas, sim, de várias, porque são múltiplas as situações que o Brasil congrega, porque são diversificadas as formas de concretização de uma dada proposta numa mesma localidade, porque são desiguais as condições concretas em que acontecem as práticas educativas, os contextos em que estão inseridos os profissionais e as populações com que trabalham. Essa realidade é múltipla e, por isso, carece de propostas também múltiplas.

É preciso que se compreendam crianças, jovens e adultos inseridos e produtores de história e cultura, que se concebam a infância e a adolescência como categorias sociais e não fases, efêmeras, que precisam ser aligeiradas em nome da modernidade e de sua ânsia de futuro e superação. É preciso, ainda, compreender e respeitar a criança, o jovem, o adulto, nas suas particularidades e diferenças, mas garantindo uma mesma qualidade, sem a qual se estaria apenas perpetuando a desigualdade, a opressão, o autoritarismo, a discriminação de gênero, o racismo e tantas outras formas de preconceito sempre contrárias à democracia. Porém, para que essa multiplicidade não se esgote numa simples diversidade, é preciso que se forje também uma sintonia. Construir a unidade na diversidade e contra a desigualdade; eis um desafio para a construção de uma proposta pedagógica que aposta na seriedade e na qualidade, também um pressuposto para orientar esta avaliação.

Mas como construir um currículo que leve em conta a heterogeneidade e que atue na direção de uma sociedade mais justa? Privilegiando fatores sociais e culturais, entendendo-os como sendo os mais relevantes para o processo educativo, porque implicam também a conquista da autonomia e da cooperação, princípios básicos da cidadania, garantindo, ainda, o enfrentamento e a solução de problemas, a responsabilidade, a criatividade, a formação de autoconceito, a vivência da linguagem nos seus vários modos de expressão. Ora, o desenvolvimento pleno e a construção/aquisição de conhecimentos acontecem simultaneamente à conquista da autonomia, à cooperação e à inserção crítica da criança na sociedade. Propor uma educação em que as crianças, os jovens e os adultos aprendam, construam/adquiram conhecimentos e se tornem autônomos e cooperativos implica pensar, ainda, 
a formação permanente dos profissionais que com eles atuam. Como os professores favorecerão a construção de conhecimentos se não forem desafiados a construírem os seus? Como podem os professores se tornar construtores de conhecimentos quando são reduzidos a executores de propostas e projetos de cuja elaboração não participaram e que são chamados apenas a implantar?

E qual o requisito para tornar uma proposta um fato presente? Além de condições materiais concretas que assegurem processos de mudança, é preciso que os professores tenham acesso ao conhecimento produzido na área da educação e da cultura em geral, para repensarem sua prática, se reconstruírem como cidadãos e atuarem como sujeitos da produção de conhecimento. E para que possam - mais do que "implantar" currículos ou "aplicar" propostas à realidade da escola, da creche, da pré-escola ou do espaço de educação em que atuam -, efetivamente, participar de sua concepção, construção, consolidação.

Como analisar/avaliar uma proposta pedagógica/currículo? Critérios sugeridos para orientar a leitura das propostas

Como disse inicialmente, toda análise supõe uma leitura. Leitura de textos falados e textos escritos, o que me permite dizer que os profissionais a que se destina uma dada proposta ou aqueles que irão avaliá-la são - ou precisam ser - seus leitores. Em Bakhtin (1992) encontro os fundamentos dessa concepção, quando ele afirma que toda leitura envolve três participantes: a leitura é sempre resultado de uma parceria ativa entre o autor, o leitor e a obra. No nosso caso, há que se perguntar sobre o(s) autor(es) da proposta e seu processo de produção, o conteúdo/produto do texto, os interlocutores a quem se dirige.

Neste segundo item procuro, então, trazer perguntas que se destinam a funcionar como critérios orientadores para uma das leituras possíveis de propostas pedagógicas de educação. Tais perguntas/critérios/ diretrizes são formuladas - talvez não fosse necessário dizê-lo - à luz dos pressupostos apresentados no primeiro momento do texto. Nunca é demais repetir que este trabalho é um roteiro - não um questionário - e, como roteiro, não pretende esgotar as questões orientadoras de análises deste tipo. Os questionamentos e as complementações ao próprio roteiro são, portanto, essenciais. 
Sobre os(as) autores(as) da proposta:

Algumas perguntas precisam ser formuladas e discutidas, bem como é necessário buscar as respostas. Dentre outras, sugiro as seguintes questões: Quem produziu a proposta? Como foi produzida? Quais os participantes dessa produção e em que condições a proposta foi elaborada?

Por outro lado, cabe indagar: O texto permite escutar/ler as vozes dos vários participantes do processo de implementação da proposta (da concepção teórica à execução prática)? O texto da proposta encontra-se escrito? Qual a concepção de proposta pedagógica do texto em análise? Supõe que a sua é uma dentre as muitas alternativas, ou a considera como a única, trazendo uma palavra monológica, autoritária, que dita o que deve e o que não deve ser feito, de maneira normativa, cheia de jargões e estruturas prontas condutoras da prática? A proposta apresenta diretrizes que resultam de experiências anteriores cujo percurso na história é resgatado, ou traz modelos a serem seguidos como se não tivessem efetivamente uma autoria, um autor vivo, nos termos de que fala Dietszch (1991), ao discutir cartilhas? Para quem o texto da proposta em questão se dirige: professores, escolas, famílias, crianças, supervisores, diretores? Dirige-se a alguém? Há indícios, no texto da proposta, de que tais leitores esperados serão levados em conta como co-autores da proposta, podendo questioná-la, modificá-la etc.? Há mecanismos de interação previstos? Quais?

Sobre o texto da proposta

A análise do texto de uma proposta precisa, de saída, considerar o que, do meu ponto de vista, mais importa no seu delineamento: Uma proposta pedagógica é um caminho, não é um lugar: Tem uma direção, um sentido, um para que, tem objetivos.

Então, cabe procurar compreender: Qual a direção, o sentido, o objetivo, o para que da proposta em análise? Os objetivos são relacionados à situação concreta da educação naquele estado ou município? Ou seja, a proposta apresentada é dimensionada à realidade da educação das crianças, dos jovens ou dos adultos daquela localidade? Há um diagnóstico, apontando dados relativos a como se encontra a educação infantil, de $1^{\circ}$ e $2^{\circ}$ graus e de adultos, na localidade em questão? 
Qual a demanda por vagas? Quantas vagas existem e quais as metas de expansão a curto, médio e longo prazos? A que instituições está vinculado o atendimento?

Ainda em relação a este ponto, outros aspectos precisam ser considerados: Quais os critérios orientadores da matrícula, no caso da oferta ser inferior à demanda? Há compromisso com a democratização do acesso? De que modo é concebida essa expansão? Tal expansão implica a construção de prédios e o concurso/contratação de profissionais? Qual a política de expansão da receita? De que modo se dá a relação da ampliação com a qualidade do serviço? Qual a política de distribuição de vagas e de garantia de condições de permanência nas creches, pré-escolas e escolas de $1^{\circ}$ e $2^{\circ}$ graus? Há garantia de ingresso das crianças e dos jovens no nível de escolaridade seguinte ao nível em questão? Ou a expectativa é de terminalidade ou interrupção da vida escolar? A permanência na faixa da escolaridade obrigatória é atendida, cumprida, pelo Estado?

E quem são as crianças, os adolescentes e/ou os adultos a quem se dirige a proposta? Quem são e quantos são os profissionais docentes e não-docentes que atuam na rede? Quais são os mecanismos de ingresso destes profissionais na rede pública (concurso, estágio, indicação, nomeação)?

Por outro lado, é fundamental perceber: Os fundamentos teóricos da proposta curricular são explicitados? Qual a concepção subjacente ou explícita de infância, homem, educação, conhecimento, cultura? Que áreas do conhecimento baseiam a proposta e qual o enfoque privilegiado? Há coerência na abordagem entre os objetivos arrolados e as ações previstas? Há coerência entre essas bases teóricas e as reais condições de implementação da proposta? Como foram trabalhados esses referenciais junto aos profissionais "elaboradores" da proposta? Que concepção de infância é tomada como referência? É coerente com as bases teóricas? Como a proposta concebe, implícita ou explicitamente, o desenvolvimento, nos seus aspectos sociais, culturais e cognitivos? Em que nível se compromete com essas concepções? A formação dos profissionais permite pensar a concepção de infância, de adolescência e de desenvolvimento nestes termos? Como são articuladas as áreas do conhecimento no interior da proposta pedagógica? Encontram significado no cotidiano escolar? Tais conhecimentos estão de acordo com as necessidades do contexto, privilegiando aspectos sociais e culturais ou são priorizados os chamados conteúdos escola- 
res universais? Ou ainda: Busca-se conciliar as necessidades do contexto ao direito de universalização dos conhecimentos para todas as crianças? Como?

Quanto à dimensão ética: que valores permeiam a proposta? Ordem e obediência; autonomia e cooperação; respeito e manutenção das diferenças; mudança e enfrentamento da desigualdade? Estão explícitos esses valores? Representam os valores da coletividade que elaborou a proposta? Respeitam a multiplicidade de valores do contexto a que se destina a proposta?

É importante também indagar: Qual a concepção de proposta pedagógica/currículo presente na proposta em análise? É um procedimento burocrático a ser cumprido ou um instrumento que, colocado nas mãos dos profissionais, pode ser apropriado e reapropriado por eles, pode ser mudado, criticado, superado? A proposta considera (i) a diversidade no ponto de partida (diferenças sociais, culturais, étnicas, éticas) tanto de crianças, jovens, famílias, populações a quem se destina, quanto dos profissionais que trabalham nas suas redes; (ii) a necessária unidade no ponto de chegada (uma mesma qualidade, acesso aos conhecimentos que são, em última instância, produzidos por todos) e, conseqüentemente, (iii) a multiplicidade de caminhos necessários? E quais as condições de organização e funcionamento das creches, pré-escolas, escolas de $1^{\circ}$ e $2^{\circ}$ graus? Como são agrupadas as crianças? Qual a relação entre o número de crianças, de jovens e de adultos e os profissionais que com eles trabalham? As salas disponíveis são compatíveis com a necessidade mínima de espaço adequado a um trabalho de qualidade? Há definição desta relação numérica (crianças, jovens ou adultos/profissionais da educação) e garantia deste espaço por parte da secretaria? O espaço educativo em questão (escola/pré-escola/creche) é organizado como espaço cultural gerador de conhecimentos? Que estratégias são buscadas como meio de assegurar as condições necessárias, mas não existentes?

Sobre os leitores a que se destina

Além de se perguntar sobre os autores e os textos que compõem a proposta, é crucial - na leitura crítica que dela se pretende fazer - considerar a que tipos de leitores ela se dirige. Ou seja, que 
modelo de homem, cidadão, sociedade lhe é subjacente? E isto é fundamental porque toda proposta contém uma aposta.

Ora, todo leitor usa critérios na sua leitura. Como leitores da proposta em questão, não podemos deixar de pensar no tipo de diálogo que o texto em análise pretende estabelecer com seus leitores. Se o seu cotidiano se expressa neste texto, se são estabelecidas pontes com o diaa-dia da escola, da creche e da pré-escola, se as reflexões que a proposta enseja permitem aos profissionais (leitores da proposta) irem além desse cotidiano, pensando-o criticamente. E, neste aspecto, ao invés de apresentar perguntas capazes de guiar tal leitura, penso ser mais adequado voltar a dizer o que é - no meu modo de entender - crucial numa proposta: como ela passa para seu leitor, ouvinte, apreciador, interlocutor a aposta que contém. E por não me contentar em fornecer aqui, como disse, pontos específicos, opto por dizer o que espero de uma proposta quando a leio, perscrutando qual é sua aposta.

Considero que não se implanta, de fora para dentro, uma proposta pedagógica, pois ela é sempre construída, e por isso acredito que no caminhar de uma proposta, ou seja, no seu longo e lento processo de construção, não há um simples ponto de chegada, mas sim um constante chegar ao conhecimento, ao saber. E esse conhecimento - nosso, das crianças, dos profissionais que com elas trabalham, dos profissionais que elaboram uma proposta (embora não sejam seus únicos autores) - pode e precisa ser lapidado com paixão, afeto, com beleza, pois é dele que fazemos o suave instrumento de nossa luta a cada dia. E nessa luta, não bastam as armas - métodos, conhecimentos teóricos, estratégias, técnicas, condições materiais. Estas são evidentemente necessárias, mas é preciso estar presente o sonho, não apenas no sentido individual, mas também de utopia e de aposta coletivas. Sonho como esperança que vai se realizando no miúdo, no presente, no todo dia, o que coloca desafios (como planejar, avaliar, arrumar o espaço, lidar com as crianças, os jovens e os adultos, que atitudes tomar, que valores adotar) a serem enfrentados prática e teoricamente, lembrando sempre que toda proposta contém uma aposta.

Assim, entendendo uma proposta pedagógica como parte de um projeto político e cultural, penso que ela está muito muito longe e não tem nada a ver com mera listagem de conteúdos ou grade curricular. Ao contrário, a proposta que é uma aposta nos liberta das tantas grades existentes na escola, na pré-escola e na creche. Grades que encarceram nossa palavra quando exigem que se fale "pedagogês", que aprisionam a escrita, a de nossas crianças, adolescentes ou adultos, quando lhes impõem 
pauta dupla, exercícios de cópia ou de cobrir pontilhado; a de nossos profissionais, quando lhes impõem fichas-modelo de planejamento, de avaliação, listas de verbos a serem empregados em objetivos operacionais etc.; grades que impedem o prazer da leitura, quando obrigam que todos façam uma única interpretação (neste caso, do texto, falado ou escrito, da proposta), que impõem um só método de ensino. Grades que nos fecham no espaço murado das instituições, das salas de aula, quando o mundo vivo de fora pede para estar do lado de dentro (o mundo da cultura, a vibração da política, a pulsão dos afetos); que douram a pílula com novidades aparentes tais como equipamentos mirabolantes, supostas teorias prontas, fórmulas e eixos salvacionistas, mas que não transformam realmente as relações de trabalho e de produção do saber; grades que prendem o trabalho pedagógico a conteúdos legitimados como escolares quando - sujeitos históricos que somos - precisamos resgatar nossa paixão pelo conhecimento e fortalecer nossa ação coletiva. É isso o que procuro encontrar numa proposta que leio, escuto, observo em ação.

E os leitores da proposta em questão? Que tipo de texto encontrarão? Qual a aposta que ele contém?

\section{Como analisar/avaliar a implementação de proposta pedagógica ou curricular? Procedimentos e critérios sugeridos}

São dois os aspectos fundamentais em relação a essa questão: uma proposta pedagógica é construída no caminho, no caminhar e toda proposta pedagógica tem uma história que precisa ser contada. Trata-se pois de conhecer como está sendo construída a proposta em questão e como (se e como) sua experiência acumulada é registrada, que mecanismos de avaliação estão sendo planejados etc. Talvez estes aspectos não possam ser obtidos diretamente da leitura dos textos, porque não tem sido usual incluir tais procedimentos, de forma sistemática, nas propostas. Mas as secretarias poderiam ser incentivadas a fazê-lo.

Ora, nesta questão - as formas de implementação - reside o eixo que, a meu ver, deveria ser central no que diz respeito à cooperação técnica a ser desenvolvida e à formação necessária dos profissionais. $\mathrm{E} o$ afirmo porque, com freqüência, por desconsiderar que no processo de implementação há prática pedagógica e conhecimentos em construção pelos profissionais, muitas propostas aparentemente bem intencionadas, 
elaboradas com seriedade e dotadas de belas intenções desgastam-se, perdem-se, ficam no discurso proclamado, nem encostam na realidade. Ou, como se diria na boa gíria do meu tempo, "nem fazem cosquinha" em termos de mudança. O discurso muda, mas tudo na prática permanece como era antes.

Inversamente, meu pressuposto é o de que uma proposta pedagógica é construída no caminho, no caminhar; não é, pois, implantada, mas plantada, enraizando-se, ramificando-se, enfrentando problemas de diversos tipos. Para tanto, uma proposta precisa $\left(1^{\circ}\right)$ ver a situação da maneira como ela se apresenta; $\left(2^{\circ}\right)$ fazer um balanço do que existe, do que falta e dos problemas a serem solucionados; $\left(3^{\circ}\right)$ com base na realidade encontrada, no balanço crítico de seus problemas e nos objetivos traçados, elaborar a proposta e as formas de colocá-la em ação; (4ํ) ser capaz de reformular-se no caminho, adaptar-se, romper ou manter práticas e processos, autoavaliar-se. Se este é o desejável, resta levantar diversas perguntas. Quanto à proposta em análise vale então perguntar: A realidade e os problemas enfrentados são diagnosticados? Há projetos prevendo sua superação? Esse diagnóstico considera que condições de funcionamento: Horário parcial ou integral; prédio próprio ou cedido; atuação direta ou convênio; número de crianças, de jovens e de adultos, por unidade, por sala de aula? O espaço é adequado para o que se pretende realizar? Que equipamentos estão disponíveis, tanto no que se refere a materiais permanentes e de consumo, quanto, e particularmente, no que diz respeito à produção cultural a que as crianças têm acesso - brinquedos, jogos, livros, jornais, revistas, filmes etc.?

E com relação aos profissionais: Qual é a formação dos profissionais que atuam com as crianças, os jovens, os adultos? Qual é sua remuneração? Que formação desejam e de que formação necessitam? Há projetos de formação permanente? Essa formação redunda em avanços na escolaridade, na carreira profissional e em salário? De que condições materiais e culturais dispõem os profissionais no que se refere a recursos permanentes, matérias de consumo e, especialmente, bibliotecas, salas de estudo, jornais, revistas, filmes para consulta, aprimoramento da prática etc.?

A formação é entendida como direito? Ou seja, formação e profissionalização são consideradas como indissociáveis, concebendo-se que as diferentes estratégias de formação devem gerar profissionalização, tanto em termos de avanço na escolaridade, quanto no que diz respeito à progressão na carreira e no aumento de salários? Há diálogo entre a administração pública e as entidades representativas das categorias 
profissionais? A administração pública possui e respeita o plano de carreira de seus profissionais?

No processo de implementação da proposta, supõe-se que a concepção e/ou adoção da proposta, pela Secretaria, e a sua divulgação em cursos ou treinamentos basta para mudar a prática cotidiana em escolas, creches e pré-escolas, priorizando-se pacotes de treinamento? Ou a implementação se alicerça na reflexão crítica da prática, com busca de novos conhecimentos e transformação dessa prática pelos sujeitos do seu próprio processo (crianças, jovens e adultos, inclusive profissionais) ? $^{3}$

Projeta-se a implementação fazendo uso do efeito multiplicador (que mais propriamente deveríamos chamar de efeito divisor, dadas as conseqüências por ele geradas em nível de fragmentação do conhecimento e das ações propostas). Supõe-se que é possível transmitir, quando não meramente repassar os conhecimentos necessários para "colocar a proposta em prática"? São utilizados encontros de vivências/oficinas, priorizando os modos de fazer sem aprofundar as teorias? Ou, ain$\mathrm{da}$, investe-se nos processos de mudança, reestruturando as relações existentes, criando eixos de formação que têm continuidade, rompendo hierarquias e atuando nos processos em que a prática pedagógica se constrói viva, quer dizer, nas unidades? Há outros caminhos alternativos instituídos nessa implementação?

Ainda no que se refere à análise das diferentes formas de implementação, cabe perguntar: Há previsão de envolvimento de outras instâncias e instituições no processo de elaboração e implementação da proposta, tais como universidades, sindicatos, centros de pesquisa e de formação de professores? Como estas parcerias foram definidas? Qual sua forma de ação? Por outro lado, pretende-se atingir toda a rede ou há delineamento de projetos-piloto? De que modo é prevista sua implementação? É viável? É acompanhada de constante avaliação por parte da comunidade da creche e/ou pré-escola e das secretarias? De que recursos se dispõem para efetivá-la (qual sua origem, montante, periodicidade)?

Enfim, a proposta em questão percebe a formação de professores como parte de um projeto de formação e emancipação cultural e prevê - para os professores, as professoras e os demais profissionais de sua rede - a realização de ações culturais, vinculadas à difusão de cinema, teatro, vídeo, espetáculos musicais, museus de arte e de ciências e bibliotecas? Que medidas concretas são previstas para viabilizá-la (convênios, acordos, eventos, parcerias etc.)? 
Ora, inicialmente apresentei meu entendimento de que uma proposta pedagógica é um caminho, não é um lugar; ela tem uma direção, um sentido, um para que, tem objetivos, que é preciso conhecer para que seja possível problematizar a prática, intervir, modificar. Em segundo lugar, defendi a idéia de que toda proposta contém uma aposta, no sentido de que ela, simultaneamente, fundamenta em - e se volta para - seu projeto de educação um determinado tipo de sociedade, de conceito de homem, de infância e de adolescência. Agora, quero expressar minha compreensão de que tanto para conceber uma proposta quanto para implementá-la, questioná-la e/ou transformá-la é preciso resgatar o que foi já feito, pois o conhecimento do hoje exige que o ontem seja colocado no centro da cena, assim como o projeto que delineia o que fazer amanhã precisa considerar o que existe e o que já foi antes realizado.

Isso significa que toda proposta pedagógica tem uma história que precisa ser contada. Toda proposta é feita no caminho, e precisa, por isso, ser falada, contada, escrita, já que fazer história supõe contá-la. Narrar a experiência individual e coletiva, relatar as ações realizadas, os obstáculos enfrentados é condição para que se possa pensar criticamente essa experiência. Assim, cabe indagar: Há registro das propostas pedagógicas anteriormente desenvolvidas pela Secretaria? Apresentam-se a origem e as razões que levaram ao delineamento da proposta em questão? Os processos vividos na elaboração da proposta, as dificuldades, os consensos ou as divergências sentidos pela equipe estão registrados? Aparecem no seu texto? Esta história da proposta é conhecida pela equipe?

Como está organizada a Secretaria no que se refere à proposta: Há equipes articuladas de trabalho ou este é realizado de maneira fragmentada, divididas as tarefas em grupos de elaboração, de implementação etc.? Há grupos de supervisão? Como funcionam? Há espaço, na proposta em questão, para que os profissionais de diferentes níveis - desde aqueles que trabalham diretamente com as crianças, os jovens e os adultos até os que ocupam os mais altos níveis hierárquicos da secretaria - conheçam seu próprio cotidiano, ou seja, para que pensem a história acontecendo, viva, presente, a "história ao vivo"? E, ainda: Existem mecanismos permanentes para relato e intercâmbio crítico de experiências (boletins, publicações periódicas da Secretaria, encontros formais ou informais)?

Os profissionais dos mais diferentes níveis são considerados como trabalhadores, respeitados nos seus direitos de cidadãos, e também na sua dimensão humana de sujeitos históricos culturais a quem 
é garantido o direito à palavra, a ter voz, a expressar pensamentos, sentimentos, posicionamentos?

Por outro lado, cabe perguntar: Há mecanismos de registro por escrito da prática, seja em nível de acompanhamento do trabalho com as crianças, os jovens e os adultos, feito pelos profissionais que com eles atuam, seja dos supervisores em relação à atuação de professores e profissionais da educação em geral? Quer dizer, existe um projeto de relato das ações desenvolvidas, entendido como avaliação no sentido amplo, intrínseco à proposta e como parte crucial de sua implementação?

Concluindo, para recomeçar...

Os subsídios e critérios de leitura, apresentados neste artigo, voltam-se para a análise crítica de propostas pedagógicas ou curriculares e merecem uma apreciação cuidadosa. Alguns permitem uma leitura mais geral, enquanto outros se referem a itens que exigem uma leitura à luz da especificidade de cada escola, creche ou pré-escola. Por outro lado, além de serem organizadoras da análise das propostas, as perguntas aqui sugeridas constituem-se também em itens a serem considerados no delineamento de propostas. São, nesse sentido, organizadoras da análise e orientadoras da concepção e elaboração de desenhos curriculares e de sua implementação.

Além disso, a partir da minha experiência na assessoria a projetos de educação de diversas prefeituras, observo que estes subsídios podem contribuir para a definição de eixos de trabalho, quando se trata de cooperação técnica realizada com a colaboração de diferentes órgãos da gestão pública, universidades, centros de pesquisa ou de formação de professores etc. Vale notar que várias poderão ser as formas de cooperação técnica desencadeadas durante e após a leitura crítica das propostas pedagógicas; nesse sentido, cabe recomendar a secretarias e órgãos da administração pública que também levem em conta essas particularidades, sem abrir mão de uma proposta que confira unidade às suas ações.

Desafiando as dicotomias tão cristalizadas na área, todo esse processo se situa na delicada corrente de circulação do conhecimento, onde é imprescindível o diálogo ou o confronto entre o que se pesquisa so- 
bre a educação, as políticas educacionais, as propostas pedagógicas e o que é feito nos e dos diferentes projetos desenvolvidos em estados e municípios, Organizações Não-Governamentais e alternativas localizadas da rede particular. Aqui, é importante reafirmar, ainda uma vez mais, a necessidade de fomentar a pesquisa na área da educação e de levar em conta os resultados da pesquisa científica nas decisões de caráter educacional. Sem isso, torna-se difícil compreender a realidade, fazer diagnósticos e, conseqüentemente, delinear propostas pedagógicas que possam cumprir seu papel, contribuindo para a democratização da educação dirigida às diversas populações de crianças, jovens e adultos.

Enfim, como foi dito na Introdução, este texto tem caráter téoricoprático; pretende ser um instrumento de trabalho inacabado e incompleto, o que significa que precisa ser também submetido, sempre, à leitura crítica daqueles que o planejam utilizar. Concebido e concebendose igualmente de forma crítica, tal instrumento poderá apoiar a reflexão coletiva de professores e demais profissionais da educação, reunidos em processos de formação permanente, em serviço, aperfeiçoamento ou extensão, desde que tais estratégias formadoras não se limitem a pensar a escola dentro dela mesma, nem reduzam a educação à sua dimensão instrucional.

Nesse sentido, a formação ou educação de professores é percebida aqui como parte de um projeto de formação cultural, crucial para que todos nós possamos repensar nossa própria inserção hoje na escola e na cultura que nos produz e é por nós produzida. Se a vida política e cultural se manifesta em nós, a cada dia, a cada momento e em cada um de nossos atos que tornam concreta uma proposta pedagógica, a implementação precisa ser concebida garantindo a dimensão de humanidade que nos constitui. Humanidade que não podemos nos arriscar a perder; humanidade que precisamos ser capazes de assegurar no trabalho de administração, supervisão, acompanhamento de uma proposta. Humanidade assegurada como? De um lado, pela superação das condições desumanas de trabalho (falta de condições materiais; baixíssimos salários e inexistência ou não cumprimento de planos dignos de carreira), ainda tão freqüentemente presentes na grande maioria de nossas redes de educação. De outro lado, pela existência de processos humanos de trabalho, em especial processos que garantam a possibilidade de que cada qual exerça sua autonomia, sua capacidade crítica e criativa, sua condição de sujeito da história, constituído de linguagem, de narrativa. 


\section{Notas}

1. Uma versão preliminar pode ser encontrada em "Propostas pedagógicas de educação infantil: Subsídios para uma leitura crítica", elaborado a partir de encomenda da Coordenação de Educação Infantil do MEC, em novembro de 1994, que contou com a colaboração de Rita Marisa Ribes Pereira. Diferentes versões têm sido elaboradas, a partir de solicitações específicas de secretarias de educação, na minha experiência, principalmente municipais.

2. Digo bezerro de ouro pela metáfora bíblica: O descrédito no fim da educação nos faz adorar ídolos? Freqüentemente aparecem soluções mágicas, não só mas, também, na área de educação, que atuam mais por seu poder de sedução do que por sua competência, efetividade ou adequação. Sobre processos de mudança na escola e formação de professores, ver Por entre as pedras: Arma e sonho na escola (Kramer 1993).

3. Quanto às estratégias de implementação de propostas ver a coletânea Alfabetização, leitura e escrita: formação de professores em curso (Kramer 1995), em particular "Melhoria da qualidade do ensino: O desafio da formação de professores em serviço".

\section{Curricular or pedagogical proposals: Support for a critical analysis}

ABSTRACT: This text has a theoretical and practical approach - it intends to present an alternative to curriculum analyses and curriculum construction. It is based on the activities of educational consultancy as well as on educational policies, evaluation practice managed by different public institutions, and on educational research, with the purpose of aiding pedagogical proposals or curricula projects. The text is guided by a critical theory of culture and the author assumes that every pedagogical project expresses a political and cultural project. It is aimed at, in particular, professionals who work or study in public education. The analysis developed here attempted to systemize the principal questions that have to be answered in order to elaborate curricula projects.

\section{Bibliografia}

BAKHTIN, Mikhail. Estética da criação verbal. São Paulo, Martins Fontes, 1992.

BENJAMIN, Walter. Origem do drama barroco alemão. São Paulo, Brasiliense, 1984. 
Obras escolhidas. São Paulo, Brasiliense, 1987a, vol I.

Obras escolhidas. São Paulo, Brasiliense, 1987b, vol. II.

DIETSZCH, Mary Júlia. Cartilhas: A negação do leitor. In: Martins, M. H. Questões de linguagem. São Paulo, Contexto, 1991.

KRAMER, Sonia. "Privação cultural e educação compensatória: Uma análise crítica." Cadernos de Pesquisa, Fundação Carlos Chagas, São Paulo, 1982, nos 42/54-62.

"Língua escrita e formação de professores: A cara e a coroa do processo de alfabetização." Cadernos Cevec, Centro de Estudos Vera Cruz, São Paulo, 1988, nos 4/47-50.

Com a pré-escola nas mãos: Uma alternativa curricular para a educação infantil. São Paulo, Ática, 1993a.

Por entre as pedras: Arma e sonho na escola. São Paulo, Ática, 1993b.

A formação do professor como leitor e construtor do saber. In: Conhecimento educacional e formação do professor, Moreira, A.F. (org.) Campinas, Papirus, 1994.

"Currículo de educação infantil e a formação dos profissionais de creche e pré-escola: Questões teóricas e polêmicas." In: MEC/SEF/Cedi, Por uma política de formação dos profissionais da educação infantil, Brasília, 1995a.

"Subsídios para uma política de formação do profissional da educação infantil - Uma síntese." MEC/SEF/Coedi, Por uma política de formação dos profissionais da educação infantil, Brasília, 1995b.

"Carta a uma professora falando sobre escola e cidadania". In: Kramer, Sonia. Alfabetização, leitura e escrita: Formação de professores em curso. Rio de Janeiro, Papéis e Cópias e Escola de Professores, 1995c.

"Melhoria da qualidade do ensino: O desafio da formação de professores em serviço" In: Kramer, Sonia. Alfabetização, leitura e escrita: Formação de professores em curso. Rio de Janeiro, Papéis e Cópias e Escola de Professores, 1995d. 